\title{
A meta-analysis of carbon storage in Indian soils under changing land-use systems for managing soil health and ensuring food security
}

\author{
Rajeev Padbhushan ${ }^{1}$, SHEETAL SHARMA ${ }^{2}$, D Rana ${ }^{3}$, Upendra Kumar ${ }^{4}$, and Anshuman \\ Kohli $^{1}$ \\ ${ }^{1}$ Bihar Agricultural University \\ ${ }^{2}$ International Rice Research Institute \\ ${ }^{3}$ International Rice Research Instutute \\ ${ }^{4}$ National Rice Research Institute
}

June 2, 2020

\begin{abstract}
Several studies on carbon status have considered current land management practices and land use systems. There however is a need for meta-analysis study to understand the status of carbon over long periods and ways to boost its storage in soils the current scenario to ensure sustainability for securing food by improving soil health. In this context over 1786 pairs dataset from several studies were generated during period 1990-2019 had been collected from Indian experiments. The review shows that carbon status has negative effect on land uses (barren land, cultivated land, grassland, horticultural land and plantation land) over the forest land. The other land uses can be carbon equivalent to forest land by regaining the carbon stocks by 34 , $41,2,34$ and $48 \%$, respectively. If this can become possible through management practices, a large amount of atmospheric carbon dioxide can be restored in the soil and problems of climate change can be mitigated. Also, this paper is synthesized to characterize the human interventions for their effects to sequester carbon in cultivated soils. Integration of organics with chemical fertilizer in cultivated soil can be one of the better land use management strategies for restoring carbon in the soil. The effect of carbon and yield was significantly increased in integrated nutrient management by $23.2 \%$ and $1.2 \%$ (in rice) and $16.2 \%$ and $4.5 \%$ (in wheat), respectively in comparison to inorganic alone. Therefore, meta-analysis of these data sets provides information that may help the scientific community to strategically guide and plan future development initiatives.
\end{abstract}

\section{Introduction}

With 1.39 billion populations, India is the world's second largest populous country and is expected to overtake China by 2025 (UNDESA, 2019). Currently, India ranks third with the share of $7 \%$ of total carbon dioxide $\left(\mathrm{CO}_{2}\right)$ emissions in the world (IEA, 2019) but ranks twentieth in the world per capita $\mathrm{CO}_{2}$ emissions which is around 1.94 tonnes, less than half the global average of 4.8 tonnes $\mathrm{CO}_{2}$ (Ritchie and Roser, 2019). The lower value in per capita emissions of $\mathrm{CO}_{2}$ for India as when compared to the other major contributors of the world (except China) is due to inverse relationship between population of the contributors to that of per capita emissions of $\mathrm{CO}_{2}$.

Intergovernmental Panel on Climate Change (IPCC) categorized soil organic carbon (SOC) as one of five foremost carbon $(\mathrm{C})$ pools that influences land use (LU) and land use change and forestry (LUC\&F). SOC forms the major portion of the terrestrial carbon pool with reserve of about $1.5 \times 10^{3}$ to $2.0 \times 10^{3}$ billion metric tonnes of $\mathrm{C}$ in the global condition (Jobbágy and Jackson, 2000; Lal, 2016; Gaikwad et al ., 2018) whereas Indian soils stores 24.3 billion metric tonnes of C (Gupta et al ., 1994) representing two to three 
folds more than that of the atmosphere and foliage, respectively (Post et al ., 1990; Nath et al ., 2018). Forest land (FL) has been documented for amending atmospheric $\mathrm{C}$ concentration by behaving means of C source or sink (Wei et al ., 2015; Nath et al ., 2018). LUC from FL to agriculture/horticulture/ grass land/barren land/plantation caused soil degradation and soil properties resulted from intensive use, uneven terrain and changing climatic conditions (Palni et al ., 1998; Kumar et al ., 2017) may behave as C source (De Blécourt et al ., 2013; Abera and Wolde-Meskel, 2013; Guillaume et al ., 2015; Iqbal and Tiwari, 2016; Fan et al ., 2016). During the few decades earlier elevated $\mathrm{CO}_{2}$ in the atmosphere that has put forth the attention of the scientific researchers to the phenomenon of soil carbon storage (SCSt) (Negi \& Gupta, 2010) and effect of LUC (Lal, 2004). LUC from FL to other land uses resulted loss of stored SOC. Stored SOC is the product of SCSt converted from atmospheric $\mathrm{CO}_{2}$ that is utilized for photosynthesis by plants (Koppad et al ., 2016).

India is at a very risk to climate change. The melting of Himalayan glaciers and changes in the monsoons are notable changes observed due to climate change. Agriculture releases around $16 \%$ of India's total greenhouse gases (GHG) emissions. The climate change and losses of carbon from the soil has affected the soil health and ultimately crop productivity. To manage the problem of climate change, soil health and ensure food security, it is essential to sequester more carbon dioxide $\left(\mathrm{CO}_{2}\right)$ in the soil. Recent years India has worked to increase the forest cover so that to become a net $\mathrm{CO}_{2}$ sink and recent findings report that India has increased $7 \%$ of the global net leaf area in last 17 years during 2000 to 2017 . Figure 1 represents the trend of share of the FL and CL in the total land area during the period 1990 to 2017. The FL has increased from $21.5 \%$ to $23.7 \%$ while the CL has decreased from $61.1 \%$ to $60.4 \%$. This shows the efforts of the Indian governments of increasing area under forest and achieving the long-term target to fetch $33 \%$ of total area under FL cover-some 109 m.ha. from 79 m.ha.

Now management practices in the agriculture are shifting toward integrated nutrient management (INM) from inorganic alone (Sharmaet al ., 2019), conventional agriculture to conservation agriculture (Ladha et al ., 2009; Gathala et al ., 2013), and monocropping to crop rotation (Marais et al ., 2012) to restore the soil health and ensuring food security. These practices are integrated and approached through Climate Smart Agriculture Practices (CSAP) to the farmers. LUC by the appropriate land use managements (LUM) counteract several problems in the soils and help to obtain higher yields.

Conversion of FL to other LU especially to CL has occurred in want of fulfill the human needs. But past few years net emissions/removals of $\mathrm{CO}_{2}$ by the FL has negative increased during 2000-2017 due to more absorption of $\mathrm{CO}_{2}$ by the increased FL area whereas net emissions/removal of $\mathrm{CO}_{2}$ of CL and GL remain constant positive consistently (Figure 2). But still several parts of the India are there where conversion of LU has changed the soil health adversely. This resulted intensive damage to soil carbon stocks (SCS) caused impacts on soil health and imbalance in environment.

LUC is identified via conversion of FL to other LU or vice versa (Kaulet al ., 2009). The efforts to accurately quantify the effects of various LUC on the global SCSt has been carried out large scale (Defrieset al ., 2002; Achard et al ., 2004; Houghton, 2008) but very few integrated approach to understand the impact of conversion of FL to other LU has been done in Indian context. Through this study the main objective is to attain a better knowledge of the Indian pattern of SOC changes with different land uses through a comparative analysis of data sets obtained through compilation of several studies carried out in the different parts of India in a holistic manner.

The pooled findings from several studies under different ecological variable regions are analyzed through metaanalysis approach. It is a statistical tool that considers experiments to assess the magnitude and direction of treatments outcome as well as pattern and sources of heterogeneity (Hedges et al ., 1999; Koricheva et al ., 2013). This study tells about the effect of LUCon SOC changesand nutrient management practice in rice and wheat crop with a meta-analysis approach to provide a quantitative analysis. In broad, the objective of this study is to 1). Quantify the effect of LUC on SOC and SCS, 2). Effect of organic matter addition on soil health and productivity related to LUM and 3). Correlations between SOC and soil properties in different LU. 


\section{Materials and Methods}

\subsection{Study selections}

The papers were searched using specific keywords from the database of different journals and the online websites. The resulted papers were separated based on requirements keeping several criteria in mind: 1). The collected papers should have comparative study between minimum any two land uses (barren land (BL); cultivated land (CL); grassland (GL); horticulture land (HL); plantation land (PL) and forest land (FL) in Indian context,2). The collected papers should have suitable sets of soil parameters (soil $\mathrm{pH}$, bulk density (BD), cation exchange capacity (CEC), soil organic carbon (SOC) and soil carbon stock (SCS), 3). Forest land (FL) was considered as control treatment over the other land uses (BL/CL/GL/HL/PL). 4). The study paper should represent different regions of India, and 5). The study was not bounded with the particular parameters like soil types, soil classes, soil taxonomy, and management practices, cropping systems, and specific trees, grasses, crops.

For comparing SOC and crop yield to show the impact of proper management practice on to bring back the conditions of soil for restoring soil health and ensuring food security, data from supplementary file of database from Sharma et al. (2019) was used that involve compared data of integrated nutrient management (INM) and inorganic alone for rice and wheat crop.

\subsection{Land use selection}

FL was selected as control treatment and other LU (BL/CL/GL/HL/PL) was taken as other treatments for this study. FL covered all types of situations existence like open to dense forest, single species tree cover to several species tree cover, Himalayan to plain forest and low aged to high aged trees. BL was considered with no vegetations either naturally developed or developed due to anthropogenic activities. CL was considered for all the type of crops and cropping systems either grown in Himalayan valleys or plain from northern to southern part and western to eastern part. Natural GL was used with no specific grasses grown in the areas. HL includes orchards and agroforestry whereas PL includes mainly arecanut plantation, coffee plantation, mango plantation, oil palm plantation, orange plantation, pine plantation and teak plantation.

\subsection{Data compilation}

Papers (original articles, review papers and thesis) were collected and reviewed from the period 1990-2019 in context to the impact of land use change (LUC) on soil organic carbon (SOC), soil carbon stock (SCS) and other soil properties in different regions of India with an aim of finding the changes in these soil parameters due to conversion of forest to other LU. After general review, data was critically analyzed and data pertaining to FL was considered as control to understand the effect of LUC as to BL, CL, GL, HL and PL in India. Selected 1786 paired data sets from these papers were analysed using Meta-analysis to understand the impact of LUC in India in various soil depths $(0-0.15 \mathrm{~m}, 0.15-0.30 \mathrm{~m}$ and $0.30-0.45 \mathrm{~m})$.

Furthermore to understand the effect of LUM through human activities, data from supplementary file of database from Sharma et al.( 2019) was used. 338 pairs of data set of the file was Meta-analysed to show the impacts of organic matter addition with chemical fertilizers on crop yields and SOC in the rice and wheat crops of the India during the period of 1989-2016 and stating that sole dependency on chemical sources of nutrients alone could not ensure the food security of the 1.39 billion populations of India.

\subsection{Meta-Analysis: Method of analysis using diverse datasets}

Meta-analysis is a potential statistical approach to analyze the reaction of managements (BL/CL/GL/HL/PL) to control treatment (FL) from differentdistinct studies evolving a universal trend. This study has attracted researchers from all over the world for better understanding of all the variables.

Two stage-based Meta-analyses (MetaWin 2.1) were used to analyse the database and understand the comparative changes (Chakraborty et al ., 2017; Rosenberg et al ., 2000). Under this the effect size (ES) was 
calculated for individual parameter using the equation as proposed by Hedges et al. (1999):

$$
E S=\ln R=\ln \left[\frac{X_{T}}{X_{C}}\right]
$$

Where,

$\mathrm{X}_{\mathrm{T}}$-Average of response variables (SOC, SCS, yield and other parameters) of the treatments (LU),

$\mathrm{X}_{\mathrm{C}}$-Average of these variables in $\mathrm{FL}$ with control

Since, all studies were from variable conditions was the basis of multiple replications, the standard deviation calculated were based on the number of observations with simple statistically procedure.

ES from individual studies were then combined using a mixed-effect model to calculate the cumulative effect size and the 95\% confidence intervals (CIs) through bootstrapping with 4999 iterations (Adamset al ., 1997). The mixed-effect model is a random-effect Meta-analytic model for categorical data (Rosenberg et al ., 2000), assuming random variation among studies within a group and fixed variation between groups. The cumulative effect was considered significant if the CIs did not pass over zero.

Interpretation of results : Results were back-transformed and presented as change in percent caused by treatments in relation to control. Significant differences were considered only p value is less than 0.05 . The Meta-analysed value has been presented in graph to clearly show the significant effect of LUC and INM over the inorganic fertilizer alone.

\subsection{Linear model for correlation among soil properties in different land uses}

Linear model is used to understand the behavior of complex systems or analyze the experimental data. Linear regression is a statistical tool used to create a linear model. In this study datasets of LU with respect to SOC and other soil properties were analyzed. The significant changes among all soil parameters have been presented in graph to clearly show the effect of SOC on LU. The linear regression equations and $\mathrm{R}^{2}$ has been presented for individual LU in the graph.

\section{Results}

\subsection{Effect of $L U$ on soil organic carbon}

With regard to LU, negative effects of SOC were found for LU like BL, CL, GL, HL and PL as when compared to FL (Figure 3). The SOC decreased significantly for BL (-27.3\%), CL (-31.1\%), GL (-36.1\%) and PL $(-35.5 \%)$ over the FL considered as control for this study but found non-significant changed for HL $(-11.5 \%)$ in comparison to FL and this might be due to some data points were found with the positive effects but the maximum data points of ranges had come in the side of negative effects as the Figure 3 showed the mean value lied towards the negative effect. These results indicated that conversion of FL towards other land uses (BL/CL/GL/HL/PL) could readily result into decline in SOC content under most conditions. The percent negative change of SOC for all the land uses (BL/CL/GL/HL/PL) over the FL was found to be in greater in range due to variability in vegetation, soil types, climatic conditions, topography, and followed management practices in the different regions of the India.

On depth-wise the overall SOC showed negative effects for other land uses (BL/CL/GL/HL/PL) over the FL (Figure 3). In soil depth 0-15 cm, SOC decreased significantly in BL (-25.5\%) and GL (-27.5\%) over the FL but found non-significant changed for CL (-21.0\%), HL (-17.5\%) and PL (-31.1\%) in comparison to FL and this might be due to some data points were found with positive effect but the maximum data points of ranges had come in the side of negative effect as the Figure 1 showed the mean value lies towards the negative effect. The majority of management practices are being carried out in soil depth 0-15 cm that could have resulted in buildup of SOC in few cases during long-term studies for the land uses CL, HL, and PL as compared to the newly established FL in the different regions of the country. In soil depth 15-30 cm, SOC decreased significantly in BL (-29.6\%), CL (-46.5\%), GL (-41.3\%) and PL (-40.5\%)over the FL but non-significant 
changed for HL (-12.4\%) as compared to FL whereas in soil depth $30-45 \mathrm{~cm}$, SOC decreased significantly in BL (-27.7\%), CL (-54.9\%), GL (-63.7\%) and PL (-36.4\%) over the FL and non-significant changed for HL $(1.8 \%)$ in comparison to FL (Figure 3). The depth-wise results of SOC were in concurrence to the findings of overall SOC and similarly indicated that conversion of FL towards other land uses (BL/CL/GL/HL/PL) could readily result into decline in SOC content.

\subsection{Effect of land use on soil carbon stock}

Land uses change impacts the SCS in all the regions of the country. In this study, SCS was found significantly affected due to conversion of FL into other land uses (BL/CL/HL/PL) and non-significantly affected with respect to GL. The percent reduction of SCS in BL, CL, GL, HL and PL was 34.0, 41.2, 1.47, 33.5, and 47.9, respectively as compared with FL (Figure 4). The decrease in SCS for GL was found towards lower direction as compared to other land uses (BL/CL/HL/PL) over the GL could be due to minimum human interference in the region whereas the maximum interference of human exaggerated losses in SCS in CL and PL. The long-term no vegetation in BL has affected adversely towards SCS.

Depth-wise study of SCS for land use changes accorded the findings of overall result of SCS under most conditions. In soil depth 0-15 cm, SCS decreased significantly in BL (-31.9\%), CL (-38.3\%), HL (-38.0\%) and PL $(-30.2 \%)$ over the FL but found non-significant changed for GL (5.7\%) in comparison to FL (Figure 4). Even though SCS for GL was non-significantly affected as when compared with FL but the positive effects could be due to long-term vegetation prevalent in some of the regions of GL over the newly established forest. In soil depth 15-30 cm, SCS decreased significantly in BL (-41.4\%), CL (-44.6\%), HL (-31.2\%) and PL (-67.1\%)over the FL but non-significant decreased for GL $(-17.3 \%)$ as compared to FL whereas in soil depth 30-45 cm, SOC decreased significantly in BL (-35.9\%), CL (-47.6\%), GL (-14.2\%) and PL (-67.2\%) over the FL and non-significant increased for HL (-10.3\%) in comparison to FL (Figure 4).

\subsection{Effect of use of organics on crop yield and SOC}

Organics alone can maintain the soil health in a better manner as when compared to inorganic alone and integrated inorganic and organics but the yield was found comparatively lower. Several studies support that organics addition to the soil improves its health as well as ensure food security by managing yield as well as crop quality. Therefore, organics was integrated with inorganic fertilizer termed as INM and was compared with inorganic alone in rice and wheat crops (Sharma et al ., 2019) and the finding suggests that organics addition alongwith inorganic fertilizer improves the rice and wheat yield in most of the condition. The wheat yield was significantly increased in INM treatment over the treatment inorganic alone by $4.5 \%$ whereas rice yield was increased by $1.2 \%$ (Figure 5). The change in yields was 50 and $130 \mathrm{~kg} \mathrm{ha}^{-1}$, respectively in rice and wheat crop in INM treatment over the synthetic fertilizer alone. SOC was with positive effects when INM treatment was applied over the treatment inorganic alone in both rice and wheat crops. The effect of SOC was significantly increased in treatment INM in rice $(23.2 \%)$ and in wheat $(16.2 \%)$ in comparison to treatment inorganic alone (Figure 5). This result directs towards that organics addition improve SOC and ultimately enhance soil quality/health. Improvement of soil health sustain better crop yield and ensure food security.

\subsection{Correlation of SOC with soil properties in different land uses}

SOC was found significantly correlated with soil properties like BD, $\mathrm{pH}$ and CEC in most of the LU at $\mathrm{p}<0.001$. The negative correlation was observed between SOC and BD (Figure 6) whereas positive correlation was recorded between SOC and CEC (Figure 7 and 8). While for soil $\mathrm{pH}$, some of the LU was positively correlated (HL \& PL) and some of the LU are negatively correlated (BL, CL, FL \& GL). There was no significant correlation was recorded in other soil properties studied in the papers collected from different sources.

\section{Discussions}

4.1 Changes in SOC following $L U$ 
The exact quantification of SOC is very important for detecting and predicting the changes in response to altering global climate (Negi and Gupta, 2010). The present study showed that FL had a negative effect on SOC over other LU (BL/CL/GL/HL/PL), and the findings of meta-analysis, which is similar to the present information that LUC from FL to other LU may lead to decrease in SOC (Kolambukattu et al ., 2013). However, these results were not the universal condition for all the LUC because this test of heterogeneity showed noteworthy variability among studies. Large annual addition of OM in the form of leaf litter, SOC is highest in the FL, which exists in the soil due to the non-disturbance of any tillage activities and also slow decomposition rate due to prevailing low temperature in the forest resulted higher soil carbon values (Haynes, 2005; Baker et al ., 2007; Kolambukattu et al ., 2013) whereas in other LU the SOC was lower as when compared to FL is due to interference of human activities or tillage practices and higher temperature in these $\mathrm{LU}$ due to direct exposure to radiation increases the rate of mineralization resulted higher decomposition of organic matter. The decomposed organic matter releases $\mathrm{CO}_{2}$ in the atmosphere and causes loss in SOC (Ramzan et al ., 2019). Similarly in case of CL, scarce of OM addition, removal of crop residues and rigorous cultivation activities increase C losses from the soil system (Lal and Kimble, 1997; Yang et al ., 2004; Baker et al ., 2007; Smith, 2008 and Sharma et al ., 2014). The lost SOC increased the $\mathrm{CO}_{2}$ concentration of atmosphere which further resulted in global warming and climate change.

To manage climate change, it is essential to store SOC in the terrestrial ecosystem. In the terms of quantity, the change in SOC content due to LUC from FL to other LU if tried to regain can be helpful to sequester more $\mathrm{C}$ in the terrestrial system. The study shows that the scope of improvement of SOC in other LU (BL/CL/GL/PL/HL) to become C equivalent to FL can be possible by increasing SOC by $27.3 \%$ in BL, $31.1 \%$ in CL, $36.1 \%$ in GL, $35.5 \%$ in PL and $11.5 \%$ in HL as when compared to FL. This change can be possible through proper management strategy in other LU.

\subsection{Changes in SCS following $L U$}

LUC is one of the influential factors which bring changes in SCS build up. Several studies suggest that the conversion of LU from FL to other LU led to decrease in the soil quality owing to the reduced SCS. LUC from FL into other LU may act as a C source (De Blécourt et al ., 2013; Guillaume et al ., 2015; Fan et al ., 2016; Iqbal and Tiwari, 2016) and concurrently affect soil characteristics (Abera and Wolde-Meskel, 2013). Based on study about 350 m.ha. of FL has been converted to other LU (ITTO, 2002) and leads to biodiversity loss (Ahrends et al ., 2015) and SCSt losses of 20-40\%(De Blécourtet al ., 2013 and Guillaume et al ., 2015).A Meta-analysis reported that SCS decreased $13 \%$ to $42 \%$ when native FL was converted to PL and CL, respectively (Guo and Gifford, 2002). Similarly in this study the negative effect of SCS on other LU was observed in comparison to FL. The lower SCS for PL and HL was recorded in this study as compare to FL might be because of the absence of deep rooted trees and fewer canopy covers. The potential for soils to restore $\mathrm{C}$ from the atmosphere is affected by the balance between rate of deposition of the photosynthetic materials and rate of respiration to decompose the $\mathrm{C}$ inputs (Mathieuet al ., 2015). In addition, as root tissue is recalcitrant for degradation and mineralization than the top soil litters therefore root derived $\mathrm{C}$ has long residence time (Rasse et al ., 2005). More accumulation of organic matter can reduce the leaching (Kenye et al ., 2019). Also, absence of canopy covers, the exposure of direct solar radiation thereby increases the rate of mineralization.

The present study shows that the scope of improvement of SCS in other LU (BL/CL/GL/PL/HL) to become C equivalent to FL can be possible by increasing SCS by $34.0 \%$ in BL, $41.2 \%$ in CL, $1.47 \%$ in GL, 33.5\% in HL and $47.9 \%$ in PL as when compared to FL. The changes of SCS can be supported by the study depth-wise on SCS. However this change is more in depths as compared to surface soil is due to LUC leads to difference in SCS is more at subsurface soil over the surface soil. Regaining the lost SCS amount under different LU is a tedious work. If this can become possible through management practices, a large amount of atmospheric $\mathrm{CO}_{2}$ can be restored in the soil and problems of climate change can be mitigated. Integration of organics with chemical fertilizer in cultivated soil can be one of the better LUM strategies for restoring $\mathrm{C}$ in the soil and improving the crop productivity and thus managing soil health and ensuring food security.

\subsection{Improving SOC through nutrient management strategy}


Intensive monocropping system, fertilizer-responsive varieties and continuous imbalanced chemical fertilization have caused losses in SOC (Singh et al., 1999) and soil health (Anwar et al. , 2005; Kumar et al ., 2017 and Kumar et al. , 2018), that leads to unsustainable crop production. Organic matter (OM) addition usually acts as a "revolving nutrient fund" and as an agent to improve soil structure, maintain tilth and minimize erosion (www.fao.org) and thus converts the unsustainable to sustainable crop production system. The OM addition rapidly gaining favor but, owing to the problems related to the lack of supply of a good quality and quantity of the added materials, the system may not be sufficient to achieve and sustain the crop production for food security (Kumar et al ., 2018). Therefore, it is essential to maintain quality OM for good produce.

Balanced and INM can maintain OM levels in the soil have been well established. The INM system improves soil health through building up SOC and improving soil properties. Integrating organic and inorganic sources can help in the sustenance of farming for a longer period than chemical fertilizer alone (Sharma et al ., 2019). The present study observed that in case of INM over the inorganic alone, as the SOC status increases in the soil it helps to improve the yield of rice and wheat crop. The finding directs that SOC improves the soil physical, chemical and biological quality that provides suitable conditions for crop growth and result into good crop. Rice and wheat are the major staple food of India and main source of energy. Achieving its optimum yield level based on soil, climate and atmospheric condition will help to meet out the food security for ever growing population of India.

\subsection{Effects of SOC on soil health and food security}

Greenhouse gases (GHG) are the main player to maintain the global energy balance. A small change in their amount in the atmosphere can affect the climatic conditions on earth. Anthropogenic emissions of $\mathrm{CO}_{2}$ are likely to increase as in the future human population increases. Human led LUC can result into significant exchanges of $\mathrm{CO}_{2}$ between the soil and air (Lal, 2000). Therefore, restoration of $\mathrm{C}$ in the soil can only be option to counteract the effect of climate change and the problems created due to climate change. Since OM plays a multifaceted role in several soil processes (Gregorich et al ., 1994) hence, SOC is the panacea for sustaining soil health and food security by the maintenance of production system (Anantha et al ., 2018).

The findings suggest SOC is related to different soil properties like BD, CEC and Soil pH. Similar strong correlations has been reported in several studies of different aspects (Pal and Pawar, 2013; Wang et al ., 2014; $\mathrm{Xu}$ et al ., 2019). The result supports that LUC affect not only SOC but also other soil properties. Some studies have derived correlations between SOC and total nitrogen (TN) and other parameters suggesting OM turnover influences these factors (Xu et al ., 2019).

Increasing attention is being focused on the role of managing and carbon storage in the soil. However, it is a major challenge to maintain or improve low level of SCS due to LUC. Proper management strategies can be utilized to mitigate this problem.

\section{Conclusion}

Based on the analysis the following conclusions were drawn: (i) LUC from FL to other LU (BL/CL/GL/HL/PL) have negative effect on SOC, (ii) SCS decreased minimum by $2 \%$ in GL, $42 \%$ in CL and maximum by $48 \%$ in PL, (iii) In general, LUC increased SOC and SCS difference on increasing soil depth, (iv) Organics addition alongwith chemical fertilizers increased crop productivity and SOC could be one the viable options in LUM for soil health and food security, and (v) A negative correlation between SOC and $\mathrm{BD}$ while positive correlation between SOC and CEC was recorded in different LU.

\section{Acknowledgement}

We are thankful to all the researchers whose contributions have been used for study analysis and referenced in this paper, which have helped us to prepare this review study.

\section{Conflict of Interest Statement}

No potential conflict of interest is reported by the authors. 


\section{References}

Abera, G., Wolde-Meskel, E., (2013). Soil properties, and soil organic carbon stocks of tropical andosol under different land uses. Open Journal of Soil Science 3, 153-162. https://doi.org/10.4236/ojss.2013.33018.

Achard, F., Eva, H.D., Mayaux, P., Stibig, H.-J., Belward, A. (2004). Improved estimates of net carbon emissions from land cover change in the tropics for the 1990s. Global Biogeochemical Cycles 18, DOI: $10.1029 / 2003$ GB002142

Adams, D. C., Gurevitch, J., \& Rosenberg, M. S. (1997). Resampling tests for meta-analysis of ecological data. Ecology, 78 (4), 1277-1283. https://doi.org/10.1890/0012-9658

Ahrendsa, A., Hollingsworth, P. M., Zieglerc, A. D.,Foxd, J. M. Chena, H., Sua, Y., XuJ. (2015). Current trends of rubber plantation expansion may threaten biodiversity and livelihoods. Global Environmental Change 34, 48-58 http://dx.doi.org/10.1016/j.gloenvcha.2015.06.002.

Anantha, K.C., Majumder, S.P., Padhan, D., Badole, S. Datta, A., Mandal, B. and Gade, K.R. (2018).Carbon dynamics, potential and cost of carbon sequestration in double rice cropping system in semi-arid southern India. Journal of Soil Science and Plant Nutrition , 18, 1-15 http://dx.doi.org/10.4067/S071895162018005001302

Anwar, M.; Patra, D.D.; Chand, S.; Kumar, A.; Naqvi, A.A.; Khanuja, S.P.S. (2005).Effect of organic manures and inorganic fertilizer on growth, herb and oil yield, nutrient accumulation, and oil quality of French basil. Communications in Soil Science and Plant Analysis . 36, 1737-46. https://doi.org/10.1081/CSS-200062434

Baker, J. M., Ochsner, T. E., Venterea, R. T., \& Griffis, T. J. (2007). Tillage and soil carbon sequestration-What do we really know? Agriculture, Ecosystems and Environment , 118 (1-4), 15. https://doi.org/10.1016/j.agee.2006.05.014

Chakraborty, D., Ladha, J.K., Rana, D.S. et al. (2017). A global analysis of alternative tillage and crop establishment practices for economically and environmentally efficient rice production.Scientific Report 7, 9342. https://doi.org/10.1038/s41598-017-09742

De Blecourt, M., Brumme, R., Xu, J., Corre, M.D., Veldkamp, E., (2013). Soil carbon stocks decrease following conversion of secondary forests to rubber (Hevea brasiliensis ) plantations. PLoS One 8. https://doi.org/10.1371/journal.pone.0069357

DeFries, R.S., Houghton, R.A., Hansen, M.C., Field, C.B., Skole, D., Townshend, J. (2002).Carbon emissions from tropical deforestation and re-growth based on satellite observations for the 1980s and 90s.Proceedings of the National Academy of Sciences USA 99, 14256-14261. DOI: 10.1073/pnas.182560099

Fan, S., Guan, F., Xu, X., Forrester, D.I., Ma, W., Tang, X., (2016). Ecosystem carbon stock loss after land use change in subtropical forests in China. Forests 7, 142. https://doi.org/10.3390/f7070142

Gaikwas, S.D., Kumar, E. K., and Gude, S. (2018). Spatial Patterns of Soil Organic Carbon Stocks in different land se system in SaleeteTaluka of Goa. Multidisciplinery International Conference on Green Earth: A Pararomic view ISBN: 978-81-923628-5-4.

Gregorich, E.G., Carter, M.R , Angers, D.A., Monreal, C.M., Ellert, B.H., 1994. Towards a minimum data set to assess soil organic matter quality in agricultural soils. Canadian Journal of Soil Science, 74, 367-85. https://doi.org/10.4141/cjss94-051

Guillaume, T., Muhammad, D., Kuzyakov, Y., 2015. Losses of soil carbon by converting tropical forest to plantations: erosion and decomposition estimated by $813 \mathrm{C}$. Global Change Biologyhttps://doi.org/10.1111/gcb.12907

Guo, L.B. and Gifford, R.M. (2002). Soil Carbon Stock and Land Use Change: A Meta Analysis. Global Change Biology , 8, 345-360. https://doi.org/10.1046/j.1354-1013.2002.00486.x 
Gupta, R. K. and Rao, D.L.N. (1994).Potential of wastelands for sequestering carbon by reforestration. Current Science, 378-389. https://www.jstor.org/stable/24098762

Haynes, R. J. (2005). Labile organic matter fractions as central components of the quality of agricultural soils: An overview.Advances in Agronomy , 85, 221268. DOI:10.1016/S0065-2113(04)85005-3

Hedges, L. V., Gurevitch, J. \& Curtis, P. S. (1999).The meta-analysis of response ratios in experimental ecology. Ecology, 80, 1150-1156. DOI: 10.2307/177062

Houghton, R.A. (2008). Carbon flux to the atmosphere from land-use changes: 1850- 2005 . In: TRENDS: A Compendium of Data on Global Change, Carbon Dioxide Information Analysis Center, Oak Ridge National Laboratory, U.S. Department of Energy, Oak Ridge, TN, U.S.A. https://cdiac.essdive.lbl.gov/trends/landuse/houghton/houghton.html

http://www.fao.org/faostat/en/

http://www.fao.org/home/en/

International Energy Agency, (2019). https://www.iea.org/reports/global-energy-co2-status-report-2019

Iqbal, S., Tiwari, S.C., 2016.Soil organic carbon pool under different land uses in Achanakmar Amarkantak Biosphere Reserve of Chhattisgarh, India. Current Science 110: 771-773. https://doi.org/10.18520/cs\%2Fv110\%2Fi5\%2F $771-773$

ITTO (2002).ITTO Guidelines for the Restoration, Management and Rehabilitation of Degraded and Secondary Tropical Forests.Policy Development Series $13 . \quad$ ITTO, Yokohama.https://www.cifor.org/library/1175/itto-guidelines-for-the restoration management-and rehabilitation-of-degraded-and-secondary-tropical-forests/ ISBN: 4-902045-01-X

Jobbágy, E.G., Jackson, R.B. (2000). The vertical distribution of soil organic carbon and its relation to climate and vegetation.Ecological Applications , 10, 423-36. https://doi.org/10.1890/10510761(2000)010[0423:TVDOSO $] 2.0 . \mathrm{CO} ; 2$

Kalambukattu, J. G., Singh,R., Patra, A. K. and ArunkumarK. (2013).Soil carbon pools and carbon management index under different land use systems in the Central Himalayan region, Acta Agriculturae Scandinavica, Section B - Soil \& Plant Science , 63, 3, 200-205, https://doi.org/10.1080/09064710.2012.749940

Kaul, M., Dadhwal, V.K. and Mohren, G.M.J. (2009). Land use change and net C flux in Indian forests. Forest Ecology and Management , 258, 100-108 https://doi.org/10.1016/j.foreco.2009.03.049

Koppad, A.G., Janagoudar, B.S., Rajakumar G.R. (2016).Influence of forest types on soil Carbon sequestration in uttara Kannada district as assessed by Remote Sensing and GIS technique. International Journal of Remote Sensing 83 Geoscience (IJRSG), 5 (3), 20-23 ISSN No: 2319-3484

Koricheva, J., Gurevitch, J., Mengersen, K., 2013. Handbook of Meta-analysis in Ecology and Evolution. Princeton University Press ISBN: 9780691137285

Kumar, U.; Nayak, A.K.; Shahid, M.; Gupta, V.V.S.R.; Panneerselvam, P.; Mohanty, S; Kaviraj, M.; Kumar, A.; Chatterjee, D.; Lal, B; Gautam, P; Tripathi, R.; and Panda, B.B. (2018). Continuous application of inorganic and organic fertilizers over 47 years in paddy soil alters the bacterial community structure and its influence on rice production.Agriculture Ecosystem Environment . 262, 65-75. https://doi.org/10.1016/j.agee.2018.04.016

Kumar, U.; Shahid, M.; Tripathi, R.; Mohanty, S.; Kumar, A.; Bhattacharyya, P.; Lal, B.; Gautam, P.; Raja, R.; Panda, B.B.; Jambhulakar, N.N.; Shukla, A.K.; Nayak, A.K. (2017). Variation of functional diversity of soil microbial community in sub-humid tropical rice-rice cropping system under long-term organic and inorganic fertilization. Ecological Indicators 73, 536-543. https://doi.org/10.1016/j.ecolind.2016.10.014 
Ladha, J.K., V. Kumar, M.M. Alam, S. Sharma, M.K. Gathala, P. Chandna, Y.S. Saharawat, and V. Balasubramanian. (2009). Integrating crop and resource management technologies for enhanced productivity, profitability and sustainability of the rice-wheat system in South Asia. p. 69-108. In J.K. Ladha et al. (ed.) Integrated crop and resource management in the rice-wheat system of South Asia. IRRI, Los Banos, the Philippines ISBN : 9789712202476

Lal, M., Singh, R. (2000).Carbon sequestration potential of Indian forests. Environmental Monitoring and Assessment 60, 315-327. https://doi.org/10.1023/A:1006139418804.

Lal, R. (2004). Soil carbon sequestration impacts on global climate change and food security. Science, 304 (5677), 1623-27 https://www.c-agg.org/wp-content/uploads/1623.pdf

Lal, R. (2016). Soil health and carbon management.Food and Energy Security , 5 (4), 212-222. https://doi.org/10.1002/fes3.96

Lal, R., Kimble, J.M. (1997). Conservation tillage for carbon sequestration. Nutrient Cycling in Agroecosystems , 49, 243-253 https://doi.org/10.1023/A:1009794514742

M.K. Gathala, V. Kumar, P.C. Sharma, Y.S. Saharawat, H.S. Jat, M. Singh, A. Kumar, M.L. Jat, E. Humphreys, D.K. Sharma, S. Sharma, J.K. Ladha. (2013). Optimizing intensive cereal-based cropping systems addressing current and future drivers of agricultural change in the northwestern Indo-Gangetic Plains of India. Agriculture Ecosystem and Environment , 177, 85-97 DOI: 10.1016/j.agee.2013.06.002

Marais, A., Hardy, M., Booyse, M., and Botha, A. (2012) Effects of monoculture, crop rotation and soil moisture content on selected soil physicochemical and microbial parameters in wheat fields. Applied and Environmental Soil Science, Volume 2012, Article ID 593623, 13 pages, https://doi:10.1155/2012/593623

Mathieu J. A., Hatte C., Balesdent, J. et al. (2015). Deep soil carbon dynamics are driven more by soil type than by climate: a worldwide meta-analysis of radiocarbon profile. Global Change Biology , 21, 4278-92 DOI: $10.1111 / \mathrm{gcb} .13012$

Nath, A.J., Brahma, B., Sileshi,G. W., Das, A. K. (2018).Impact of land use changes on the storage of soil organic carbon in active and recalcitrant pools in a humid tropical region of India. Science of the Total Environment , 624, 908-917 https://doi.org/10.1016/j.scitotenv.2017.12.199

Negi, S. S., and Gupta, M.K. (2010). Soil organic carbon store under different land use systems in Giri catchment of Himachal Pradesh,Indian Forester , 136(9), 1147 ISSN: 0019-4816

Palni, L.M.S., Maikuri, R.K., Rao, K.S., (1998). Conservation of the Himalayan agroecosystem: issues and priorities. In: Technical Paper-V in Eco regional Cooperation for Biodiversity Conservation in the Himalaya. United Nation Development Programme, New York, pp. 253-290.

Post, W.M., and Mann, L.K. (1990).Changes in soil organic carbon and nitrogen as a result of cultivation. Soils and the greenhouse effect, 401-06 DOI: 10.3334/CDIAC/tcm.006

Ramzan, S., Zahoor, I. Ahmad, P., Ashraf, I., Wani, M. A. and Rasool, R. (2019).Effect of Agricultural Land-use on Carbon Sequestration in Soils.Biological Forum-An International Journal, 11(1): 117-25 ISSN No. (Print): 0975-1130 ISSN No. (Online): 2249-3239

Rasse D.P., Rumpel C., Dignac M.F. (2005). Is soil carbon mostly root carbon? Mechanisms for a specific stabilization. Plant and Soil , 269, 341-56 DOI: 10.1007/s11104-004-0907-y

Ritchie, H. and Roser, M. (2019). $\mathrm{CO}_{2}$ and Greenhouse gases Emissions. Published online at Our World In Data.org. Retrieved from: 'https://ourworldindata.org/co2-and-other-greenhouse-gas-emissions' [Online Resource]

Rosenberg, M. S., Adams, D. C. \& Gurevitch, J. MetaWin. (2000) Statistical Software for Meta-Analysis Version 2.0.Sinauer Associates: Sunderland, MA. ISBN: 0878937609 
Sharma, S., Padbhushan, R. and Kumar, U. (2019). Integrated Nutrient Management in Rice-Wheat Cropping System: An Evidence on Sustainability in the Indian Subcontinent through Meta-Analysis. Agronomy , 9, 71 https://doi.org/10.3390/agronomy9020071

Sharma, V., Hussain, S., Sharma, K.R.,Arya,V. M. (2014).Labile carbon pools and soil organic carbon stocks in the foothill Himalayas under different land use systems. Geoderma 232-234, 81-87 https://doi.org/10.1016/j.geoderma.2014.04.039

Singh, R.P.; Mundra, M.C.; Gupta, S.C.; and Agrawal, S.K. (1999).Effect of integrated nutrient management on productivity of pearl millet-wheat cropping system. Indian Journal of Agronomy , 44 (2), 250-253.

Smith, P. (2008). Land use change and soil organic carbon dynamics.Nutrient Cycling in Agroecosystems , 81, 169-178 https://doi.org/10.1007/s10705-007-9138-y

United Nations Department of Economic and Social Affairs: Population Division, 2019 https://www.un.org/en/development/desa/population/index.asp

Wei, X., Shao, M., Gale, W. et al. (2015). Global pattern of soil carbon losses due to the conversion of forests to agricultural land. Scientific Reports 4, 4062. https://doi.org/10.1038/srep04062

Xu S, Liu X, Li X, Tian C. (2019). Soil organic carbon changes following wetland cultivation: a global meta-analysis. Geoderma347, 49-58.

https://doi.org/10.1016/j.geoderma.2019.03.036

Yang, Z., Singh, B. \& Sitaula, B. (2004). Fractions of organic carbon in soils under different crop rotations, cover crops and fertilization practices. Nutrient Cycling in Agroecosystems. 70 , 161-166

https://doi.org/10.1023/B:FRES.0000048479.30593.ea

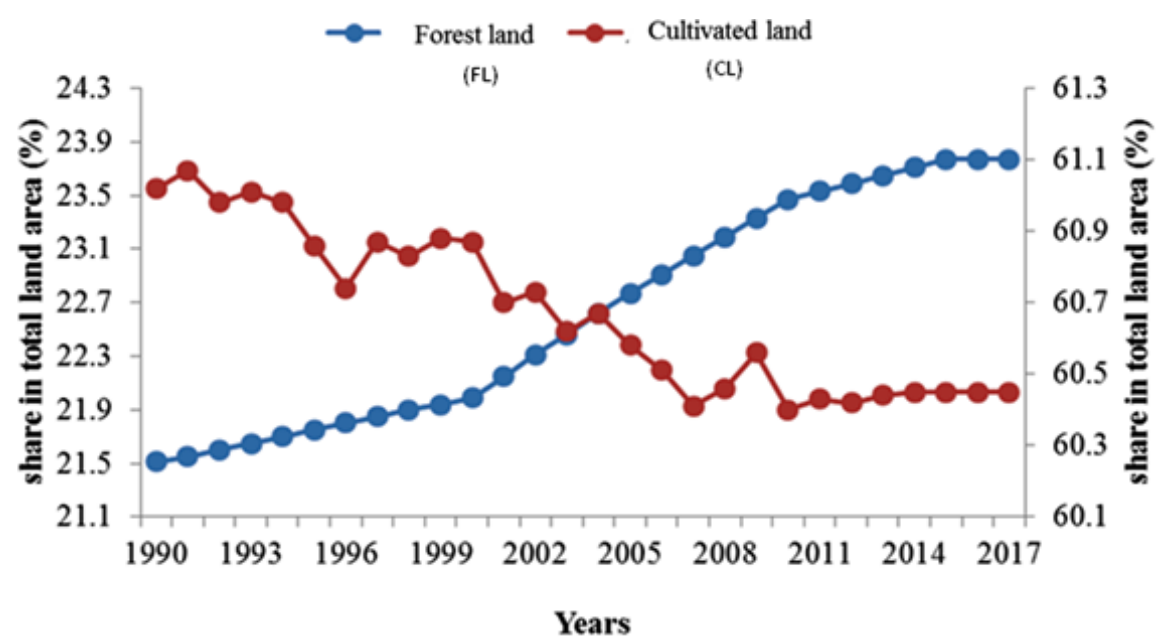



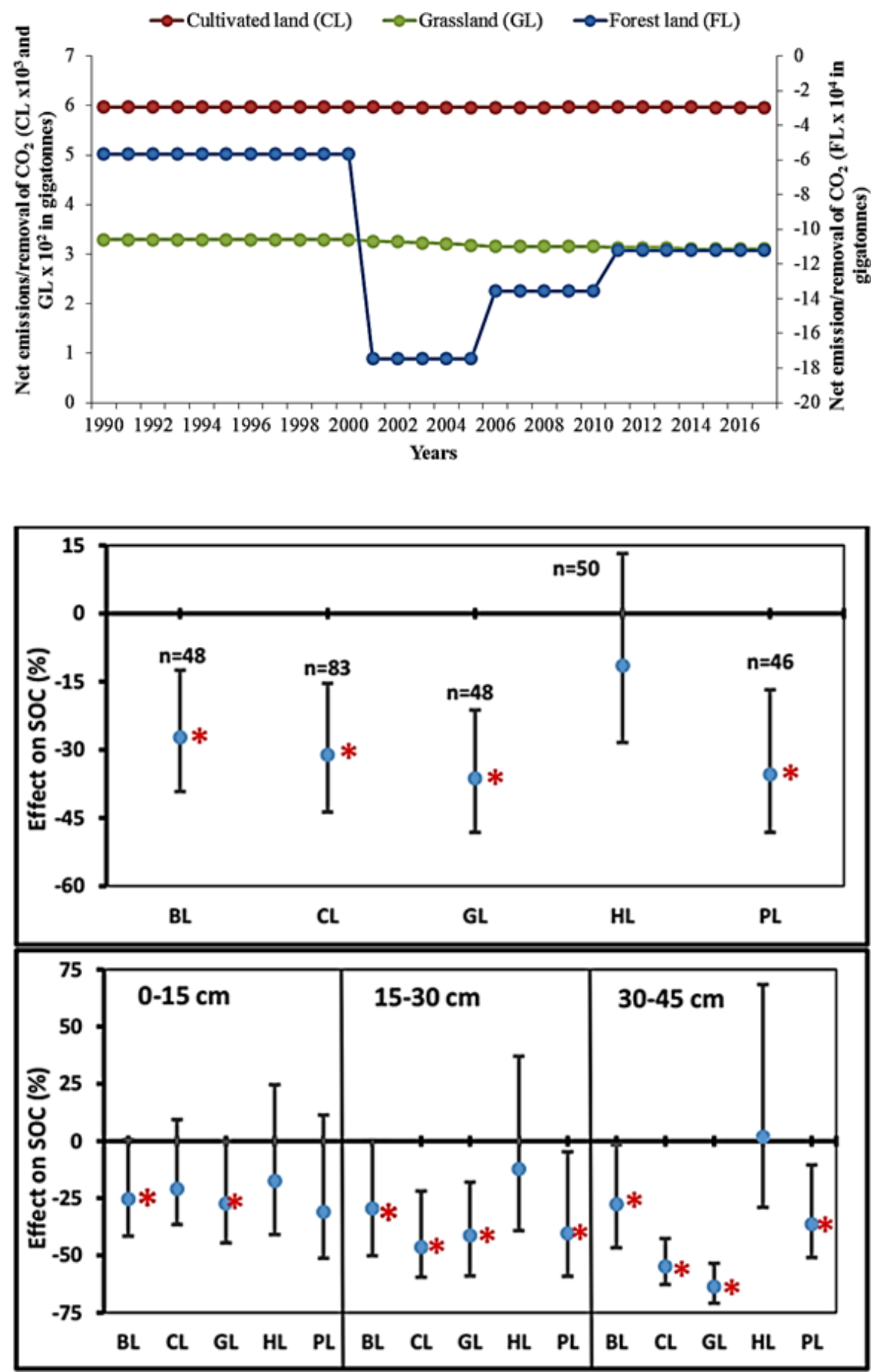

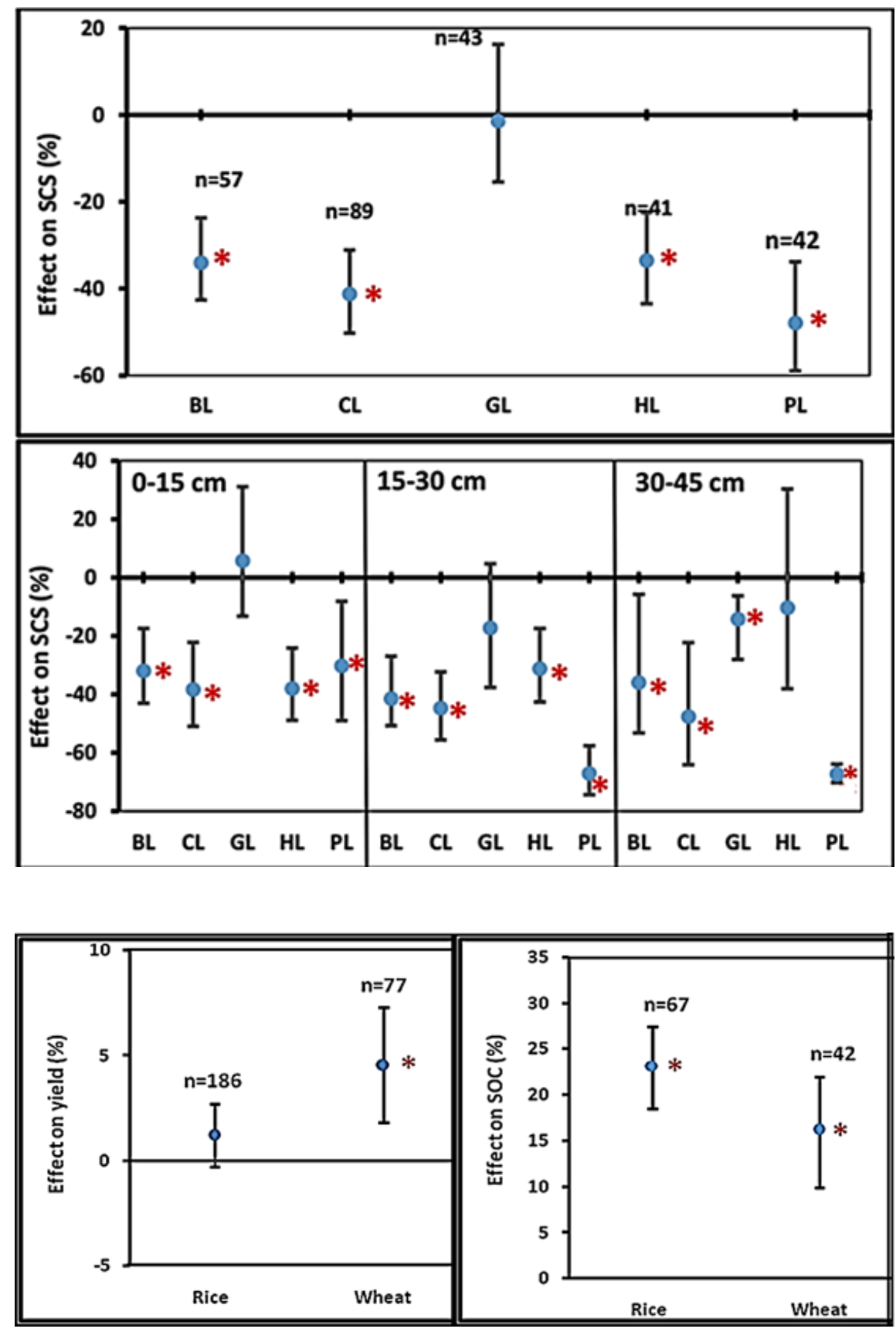

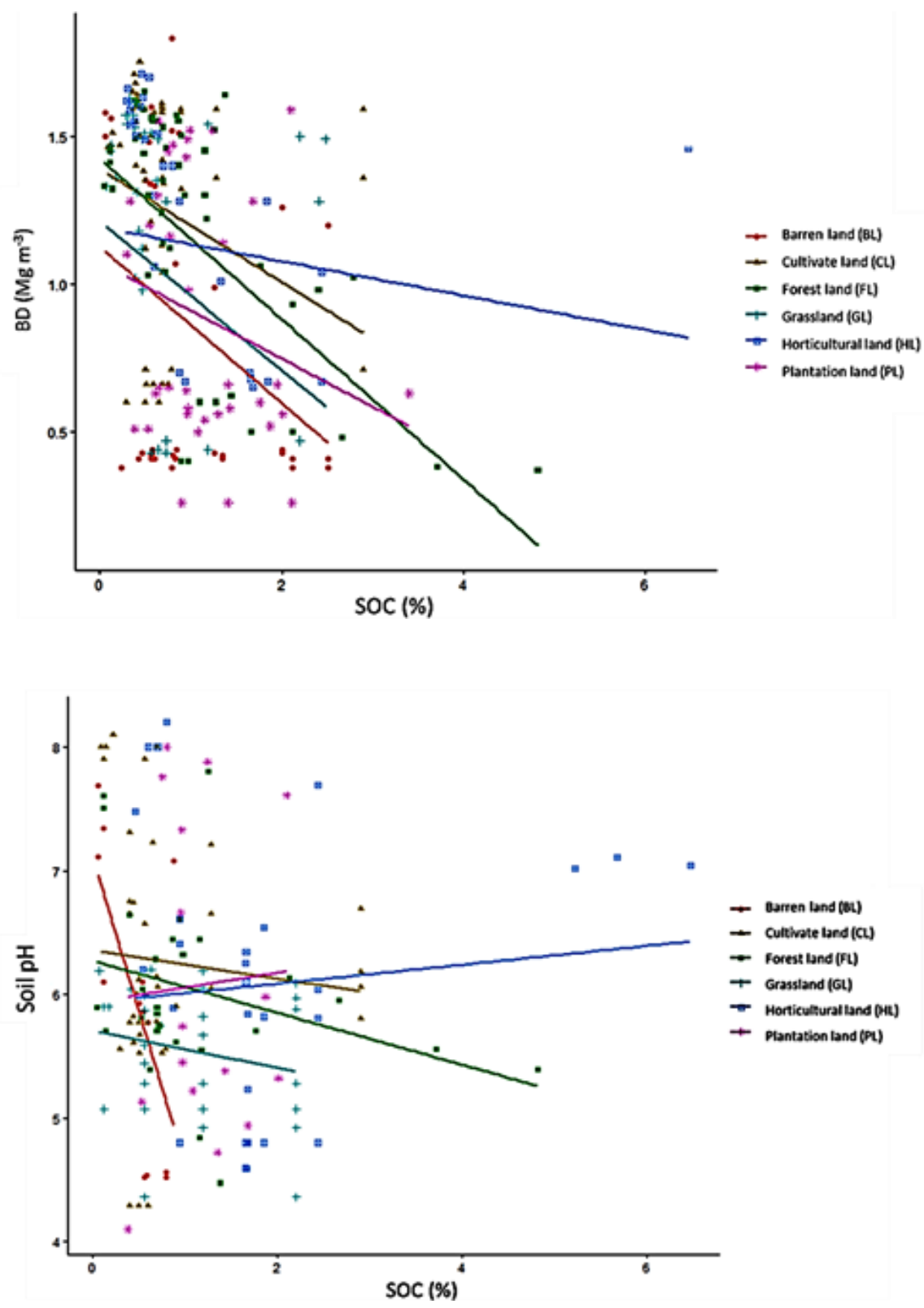


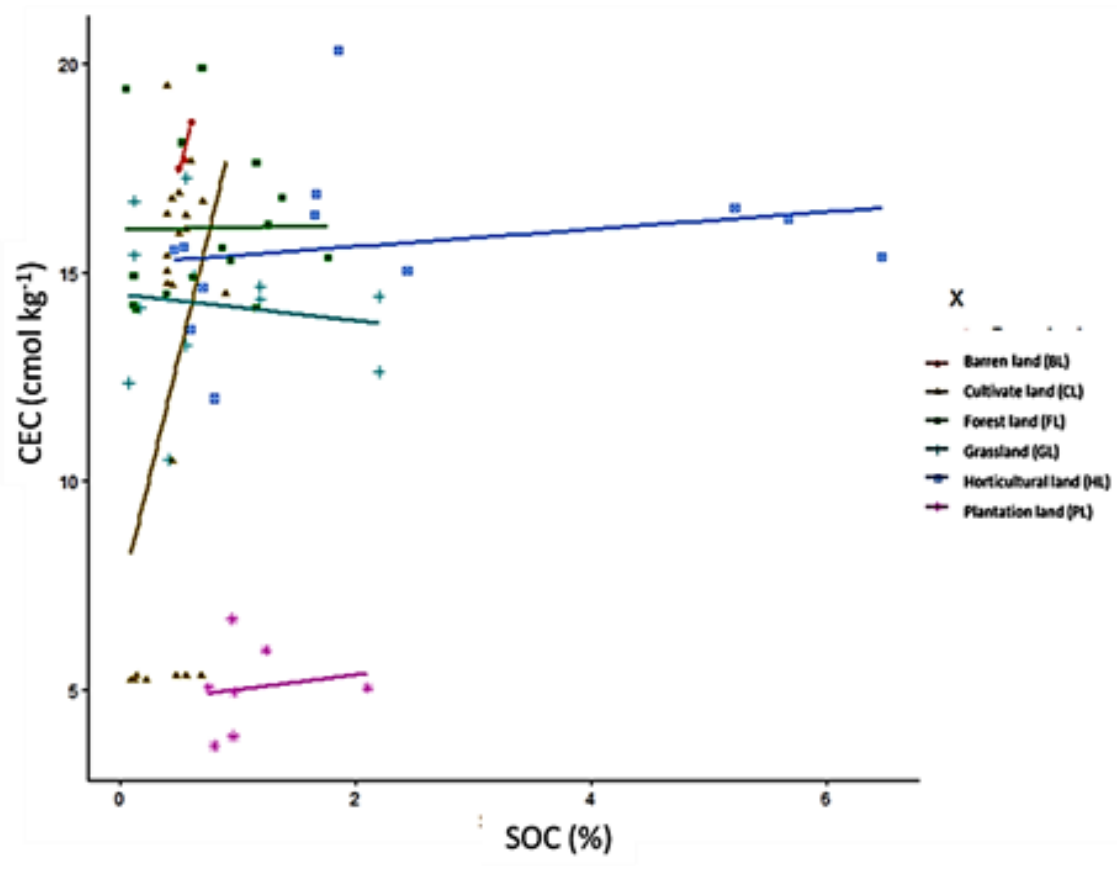

